\title{
Experimental analysis of waste tyres as a sustainable source of energy
}

\author{
Dina Czajczyńska ${ }^{1, *}$, Krzysztof M. Czajka ${ }^{2}$, Renata Krzyżyńska ${ }^{1}$, and Hussam Jouhara ${ }^{3}$ \\ ${ }^{1}$ Wroclaw University of Science and Technology, Faculty of Environmental Engineering, \\ Wyb. Wyspianskiego 27, 50-370 Wroclaw, Poland \\ ${ }^{2}$ Wroclaw University of Science and Technology, Faculty of Mechanical and Power Engineering, \\ Wyb. Wyspianskiego 27, 50-370 Wroclaw, Poland \\ ${ }^{3}$ College of Engineering, Design and Physical Sciences, Brunel University London, Uxbridge, \\ Middlesex UB8 3PH, UK
}

\begin{abstract}
Nowadays, the stability of energy supply that additionally should be sustainable is one of the most important global issues. Thus, many new potential energy sources are being investigated. Since automobile industry is growing, a huge amount of waste tyres (WT) occur each year. Pyrolysis of scrap tyres can be considered as a sustainable way to recover significant amounts of energy as well as the valuable materials. Potential of waste tyres in the energy sector is studied in this work. Proximate, ultimate and thermogravimetric (TG) analysis of mechanically grounded WT sample was done. Waste tyres feature high heating value combined with carbon content as high as $87.90 \%$ (on dry ash-free basis). Additionally, TG analysis allows to choose optimal operating temperature for pyrolysis process which is between 350 and $500^{\circ} \mathrm{C}$. However, the sulphur content is also relatively high - around $2 \mathrm{wt} . \%$ - and it is the most important challenge for utilizing this waste in a thermochemical way.
\end{abstract}

\section{Introduction}

It is evident that the number of vehicles is growing each year. According to European Tyre \& Rubber Manufacturers' Association (ETRMA) there was 1.022 billion passenger cars in 2016 and production of tyres had reached 4.94 million tonnes. Moreover, it is estimated that the number of passenger cars will exceed 1.3 billion worldwide until 2024 [1]. Unfortunately for waste managers but luckily for drivers, all produced tyres eventually will become a difficult-to-utilize waste since they are generally very durable. There are several widely available methods of utilization of Waste Tyres (WT). For example, in Poland majority of them is combusted in cement plant where the construction of kiln and temperature approximately $2000^{\circ} \mathrm{C}$ ensures complete and safe disposal [2, 3]. Another popular way of WT processing is mechanical shredding combined with further application in asphalt, sport fields or wipers production.

\footnotetext{
* Corresponding author: dina.czajczynska@pwr.edu.pl
} 
Among sustainable energy sources, waste utilization is one of the most prominent research topics of recent years. Scrap tyres are often considered as a raw material for thermochemical processes different from combustion in order to recover energy as well as valuable chemicals. This can be achieved by pyrolysis which has been known since ancient times. It is a process that causes thermal decomposition of almost any kind of organic matter under high temperature and different pressure conditions but in the absence of oxygen. For instance, Choi et al. [4] obtained pyrolysis oil from waste tyres which contains sulphur content of less than $1 \mathrm{wt} \% \%$ together with high concentration of precious limonene and xylenes. Additionally, char treated with acid and then activated gained specific surface area as high as $437 \mathrm{~m}^{2} / \mathrm{g}$ [4]. It can be concluded, that good quality product with industrial potential were produced. Literature review concerning production of pyrolytic oils form waste tyres was made by Hita et al. [5]. In turn, Antoniou et al. [6] critically analysed activated carbon production form char. It is important to note that when comparing with traditional waste management of tyres such as combustion, pyrolysis provides lower emissions of pollutants such as polycyclic aromatic hydrocarbons, volatile organic compounds and $\mathrm{CO}_{2}$, thus it can be considered as an environmentally respectable solution [7-9]. On the other hand, a large variety of equipment possible to use in waste pyrolysis process may confused researchers and potential investors [10]. Furthermore, multiple process adjustment options also need to be studied. In this paper several analysis was investigated in order to describe and evaluate the waste tyres as a pyrolysis substrate. Many researchers investigated pyrolysis of tyre rubber, but limited information is available about pyrolysis of whole tyre samples. Thus obtained results will provide very useful information for possible application of the process in an industrial scale where probably whole WT will be utilized.

Firstly, the most basics properties that must be identified before planning waste pyrolysis are fuel parameters. Among them proximate and ultimate analysis as well as heating value may be listed. It is reported that they vary significantly depending on waste type. Some of them are presented in the Table 1. Additionally, fuel ratio (FR) defined as the content of fixed carbon (FC) divided by the content of volatile matter (V) may be investigated to highlight the quality of feedstock for thermochemical processes. The ratio of FC to V provides an indication of the ease of solid fuel ignition and subsequently gasification, or oxidation, depending on how the fuel is to be converted.

Table 1. Fuel parameters of different feedstocks for thermochemical processes.

\begin{tabular}{|c|c|c|c|c|c|c|c|c|c|c|c|}
\hline \multirow{2}{*}{ Material } & \multicolumn{4}{|c|}{$\begin{array}{c}\text { Proximate analysis, } \\
\text { wt. \% }\end{array}$} & \multicolumn{5}{c|}{ Ultimate analysis, } & $\begin{array}{c}\text { Heating value, } \\
\text { MJ/kg }\end{array}$ & Ref. \\
\cline { 2 - 15 } & $\mathbf{M}$ & $\mathbf{V}$ & $\mathbf{F C}$ & $\mathbf{A}$ & $\mathbf{C}$ & $\mathbf{H}$ & $\mathbf{O}$ & $\mathbf{N}$ & $\mathbf{S}$ & & \\
\hline MSW & 5.1 & 59.3 & 8.4 & 27.2 & 48.6 & 6.0 & 12.5 & 3.9 & 0.3 & $18.6^{\mathrm{l}}$ & {$[11]$} \\
\hline WEEE & - & 25.5 & 21.3 & 53.2 & 19.8 & 1.8 & 77.6 & 0.7 & 0.2 & - & {$[12]$} \\
\hline Cardboard & 5.4 & 79.1 & 10.0 & 10.9 & 38.0 & 4.6 & 45.6 & 0.3 & 0.3 & $13.7^{1}$ & {$[13]$} \\
\hline Spruce Wood & 8.4 & 83.5 & 16.1 & 0.4 & 48.3 & 6.3 & 44.6 & 0.3 & & $19.5^{\mathrm{h}}$ & {$[14]$} \\
\hline Biomass & 14.7 & 64.4 & 16.0 & 4.9 & 51.1 & 6.2 & 41.4 & 1.1 & 0.2 & $18.0^{\mathrm{h}}$ & {$[15]$} \\
\hline Coal & 5.5 & 30.8 & 43.9 & 19.8 & 78.2 & 5.2 & 13.6 & 1.3 & 1.7 & $25.0^{\mathrm{h}}$ & {$[15]$} \\
\hline PET & 0.6 & 86.8 & 13.2 & 0.0 & 62.5 & 4.2 & 33.30 & 0.0 & 0.0 & $22.1^{1}$ & {$[13]$} \\
\hline
\end{tabular}

$\mathrm{M}$ - moisture, A - ash, MSW - municipal solid waste, WEEE - Waste of Electrical and Electronic Equipment, ${ }^{1}-$ lower, ${ }^{\mathrm{h}}$ - higher

Secondly, also kinetics of the process, determined with the use of the thermogravimetry (TG) coupled with differential scanning calorimetry (DSC), are important for improvement of any process where waste tyres are a part of the chemical system and to determine how the waste decomposition takes place [11]. The knowledge about fuel behaviour is essential for good prediction of the ignition and burnout, the temperature profile, the product distribution of tar, char and evolved gases and the overall process efficiency. 


\section{Methodology}

\subsection{Samples preparation}

Samples of waste tyres was provided by recycling company "Recykl" located in Greater Poland, Poland. Three different-size fractions were obtained by grinding whole tyres in special mills. The smallest fraction with particle size about $0.5 \mathrm{~cm}$ was chosen for further pyrolysis experiments. It was reported in the literature that using of particle sizes below $5 \mathrm{~mm}$ does not influence on the process rate and allows to avoid temperature gradient leading to heat transfer limitations [16]. Because the whole tyre was shredded, the sample contains rubber matter as well as fibre and steel pieces.

The sample was placed indoor for a few days to reduce the moisture since the grinded tyres were kept outdoor at the company's premises, but no additional drying was applied. However, there was a necessity to carryout extra mechanical fragmentation to investigate the potential of waste tyres as a sustainable source of energy by determination of fuel parameters and TG analysis. Analytical equipment need a feedstock with particle size of up to $0.25 \mathrm{~mm}$ which was achieved by using cutting mill RETSH SM-2000.

\subsection{Determination of fuel parameters}

The proximate analysis was performed according to following standards:

1. PN-G-04511:1980 - determination of M content;

2. PN-G-04512:1980/Az1:2002 - determination of A content;

3. $P N-G-04516: 1998$ - determination of volatile matter content.

The fixed carbon was accounted from a mass balance to $100 \mathrm{wt} . \%$ based on M, V, A share. The ultimate analysis was done in accordance with:

1. $P N-G-04571$ - determination of carbon, nitrogen and hydrogen content by using automatic analyser Leco TruSpec CHNS, and

2. PN-ISO 35 - determination of total sulphur content.

The share of oxygen was defined indirectly by difference.

Additionally, the heating value was investigated according to $P N-C-04375-2: 2013-07$. The higher heating value (HHV) was measured in calorimeter IKA C2000 and the lower heating value (LHV) was accounted based on Equation (1):

$$
L H V=H H V-24,42 \cdot(M+8.9 \cdot H)
$$

\subsection{Thermogravimetric analysis}

The analysis was performed by using thermogravimetry (TG) coupled with differential scanning calorimetry (DSC). The simultaneous TG/DSC measurement enables determination of a mass loss and a heat flow as a function of temperature and time. Experimental tests were carried out by means of Setaram Setsys Evolution 18 thermogravimeter. Figure 1 shows the TGA/DSC used for the analysis. 

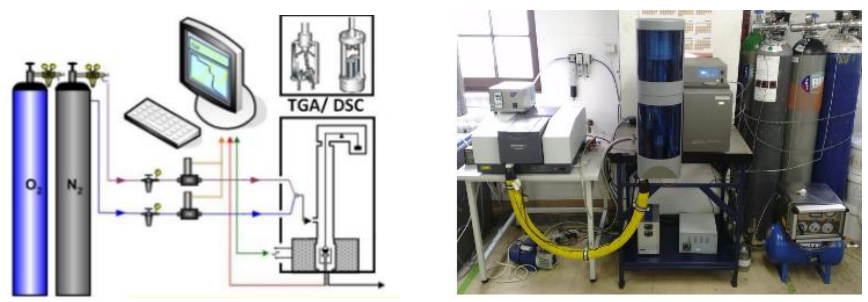

Fig. 1. The scheme and the photo of the TGA/DSC stand.

The thermogravimetric analyser comes equipped with a cylindrical, electrically heated furnace, offering heating rates up to about $100^{\circ} \mathrm{C} / \mathrm{min}$ and a maximum operation temperature up to $1500^{\circ} \mathrm{C}$. Inside the furnace, a microbalance is located with a sample pan connected to programmable control temperature. A precise control of the atmosphere ensures a gas control panel equipped with mass flow controllers.

During operation, the thermogravimeter measures the change of sample mass and the heat flow over time and temperature. For the purpose of this study, an isothermal approach is applied, due to inability to reach the high temperature without release of the most reactive volatiles [17]. The experimental procedure consist of heating about $5 \mathrm{mg}$ samples with a flow of $32 \mathrm{ml} / \mathrm{min}$ of a carrier gas. Samples are held at $120^{\circ} \mathrm{C}$ for $50 \mathrm{~min}$ in nitrogen, to remove moisture. Afterwards, to simulate pyrolysis process, samples are heated at a rate of $20^{\circ} \mathrm{C} / \mathrm{min}$, from 120 to $900^{\circ} \mathrm{C}$.

In order to represent the physical phenomenon properly under the investigated conditions, two models are applied, namely the reaction rate constant model, which assumes that the fuel is decomposed with the reaction rate $\mathrm{k}$ (model $\mathrm{B}$ ) and the multi-component model, which assumes that the fuel is decomposed through several parallel first order reactions (model A).

\section{Results and discussion}

\subsection{Determination of fuel parameters}

Waste tyres can be considered as a fuel with very good heating parameters. In contrast with other types of waste, such as biomass or MSW, waste tyres have a noticeably high heating value in-comparison with traditional solid bitumen. The lowest heating value for raw sample of waste tyres is $31.88 \mathrm{MJ} / \mathrm{kg}$ - two times higher than that for firewood (see Table 1.). Additionally, the higher and the lower heating value for dry ash-free basis was $36.83 \mathrm{MJ} / \mathrm{kg}$, and 35.31 , respectively.

Moreover, the composition of waste tyres also makes them a suitable material for pyrolysis. The results of the tyres proximate and ultimate analysis are listed in Table 2 . For dry ash-free tyre sample, volatiles and fixed carbon content are 73.31 and 26.69 wt.\%, respectively. Fuel ratio for waste tyres is 0.36 which is below the fuel ratio range of 1 to 10 that is normally used for commercial coal directed for combustion. This means that tyres become volatile much easier than traditional solid bitumen and present perfect feedstock for pyrolysis or gasification. Contrary to biomass, which is considered as a renewable energy source too, moisture content in analysed sample was only $2.3 \%$ thus tyres do not need high energy-consuming drying devices before thermochemical processes, such as pyrolysis, to take place. 
Table 2. Proximate and ultimate analysis of waste tyres.

\begin{tabular}{|c|c|c|c|c|c|c|c|c|c|}
\hline \multirow{3}{*}{$\begin{array}{l}\text { state of the } \\
\text { sample }\end{array}$} & \multicolumn{4}{|c|}{ Proximate analysis } & \multicolumn{5}{|c|}{ Ultimate analysis } \\
\hline & $\mathbf{M}$ & $\mathbf{A}$ & $\mathbf{V}$ & FC & $\mathrm{C}$ & $\mathbf{H}$ & $\mathbf{N}$ & $\mathbf{S}$ & $\mathbf{O}$ \\
\hline & \multicolumn{4}{|c|}{$\%$} & \multicolumn{5}{|c|}{$\%$} \\
\hline raw & 2.30 & 7.26 & 66.31 & 24.14 & 77.67 & 6.15 & 0.59 & 1.99 & 4.04 \\
\hline$d r y$ & & 7.43 & 67.87 & 24.70 & 79.50 & 6.29 & 0.61 & 2.04 & 4.13 \\
\hline dry ash-free & & & 73.31 & 26.69 & 87.90 & 6.95 & 0.67 & 2.26 & 2.22 \\
\hline
\end{tabular}

Furthermore, it is clearly indicated in the Table 2 . that tyres consist mainly of carbon, which is a component of rubber matter as well as carbon black which both are used for tyres production. The percentage of carbon in dry free-ash basis exceed $85 \%$. Additionally, relatively low content of nitrogen and oxygen allows to avoid high concentration of oxides in evolved pyrolysis gases. Significant concentration of carbon monoxides have been reported in literature $[18,19]$. However, sulphur content in tyres is approximately $2 \%$ since it is used as a vulcanization agent during their production process. The presence of sulphur in feedstock for pyrolysis is unfavourable, because under high temperature and oxygen-free condition it is converted to $\mathrm{H}_{2} \mathrm{~S}$ and thiols which have strong unpleasant odours and are toxic. Their removal from pyrolytic gas is one of the biggest challenges for researchers working on the commercialisation of the process $[19,20]$.

The obtained results from the waste tyre analysis are comparable with literature data, thus it is possible to conclude that the tyre sample is representative and can be used for further experiments. For instance, Kandasamy \& Gökalp [21] investigated heating value of passenger and truck tyres achieving results of 28.9 and $30 \mathrm{MJ} / \mathrm{kg}$, respectively. These are slightly lower than that presented in this paper. There was a slight higher amount of water noticed in the sample from "Recykl", but the fraction of volatiles were higher. Thus, the heating value also was higher. In turn, ultimate analysis showed the following percentage composition: $\mathrm{C}-79.1, \mathrm{H}-6.7, \mathrm{~N}-0.6, \mathrm{~S}-2.2, \mathrm{O}-2.8$ and it was almost the same as presented here. On the other hand, Gonzalez et al. [22] obtained higher heating value of analysed sample, namely $36.3 \mathrm{MJ} / \mathrm{kg}$. It contained: $0.7 \mathrm{wt} . \%$ of moisture, $8.0 \mathrm{wt} . \%$ of ash, $61.9 \mathrm{wt} . \%$ of volatiles and $29.5 \mathrm{wt} \%$ of fixed carbon. Elemental composition was as follows: $\mathrm{C}-86.7 \%, \mathrm{H}-8.1, \mathrm{~N}-0.4 \%, \mathrm{~S}-1.4 \%, \mathrm{O}-1.3 \%$, and it was a bit diverse than presented here. Some differences depending on type of tyres may appear and they were reported for passenger cars, trucks, motorbike [23] or bike tyres [24]. Obviously, also each tyre producer has its own unique composition [25], but it is still very comparable. Generally, it can be assumed that tyres compositions are fairly similar and they can be considered as a homogenous waste as well as source of sustainable energy.

\subsection{Thermogravimetric analysis}

Figure 2 depicts a heating curve and an exemplary loss of sample mass as a function of time. The obtained results indicate that the most rapid evolution of volatiles was observed between 55 and 64 minute of the experiment, which correspond to the temperature range between 350 and $500^{\circ} \mathrm{C}$ (see Fig. 3.). It was proven in further experiments that evolution of gases and vapours were most intensive in this temperature range. 


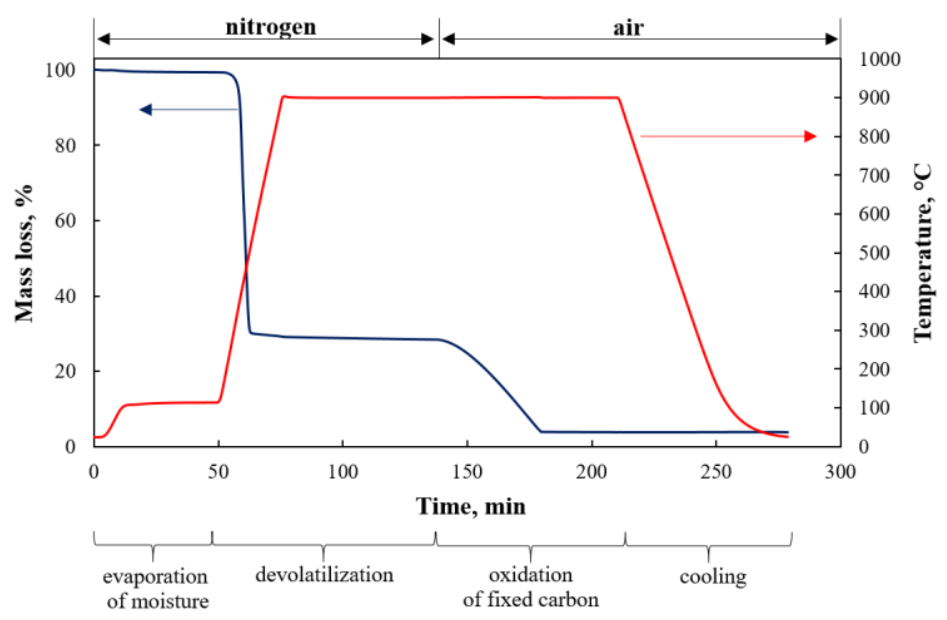

Fig. 2. Heating curve and exemplary loss of sample mass as a function of time.

The derivation of mass loss over time, known as a reactivity, indicates at least two-stage character of pyrolysis, where each stage can be attributed to the decomposition of different fractions of the investigated fuel. In order to calculate the kinetic parameters describing the evolution of each fraction, the reactivity curve was deconvoluted. Obtained curves are depicted in Fig. 4. Performed deconvolution of TG signal indicates the existence of at least one more stage (1'), confirming observations made based on the DSC measurement depicted in Figure 5. According to the DSC analysis, peak 1' may be attributed to the evolution of highly reactive volatiles, being the early stage of pyrolysis $\left(\mathrm{ca} .350^{\circ} \mathrm{C}\right.$ ). Additionally, from Figure 5 a highly exothermic reaction (peak 3) not associated with the loss of mass is observed. This can be attributed to the change of carbon structure or ash transformation.

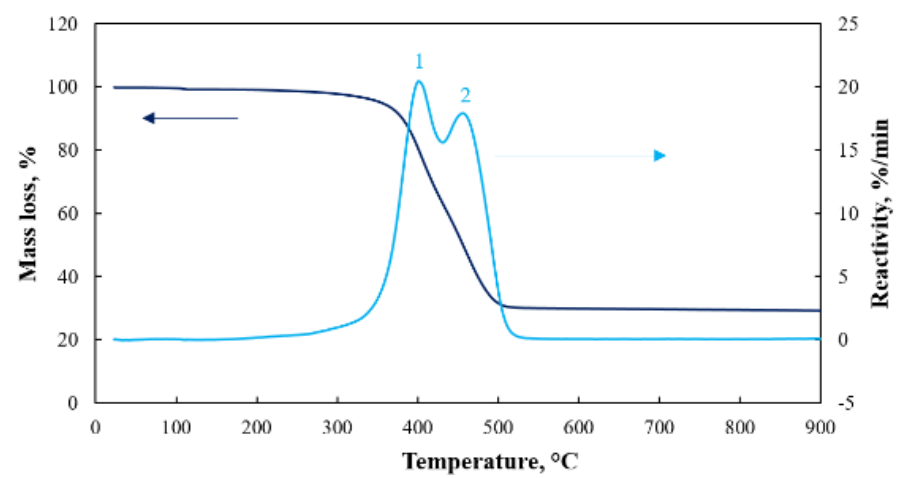

Fig. 3. Mass loss and reactivity curves presented as a function of time. 


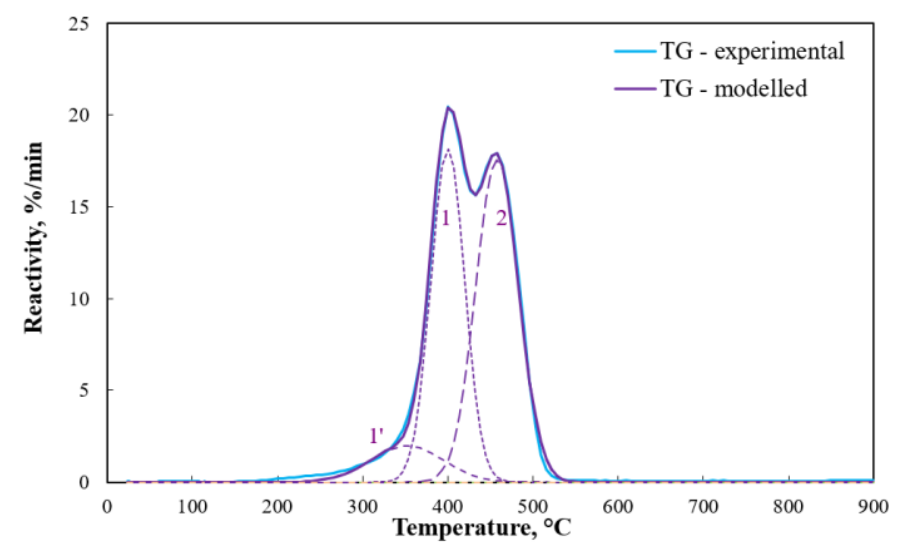

Fig. 4. Deconvolution of reactivity curve.

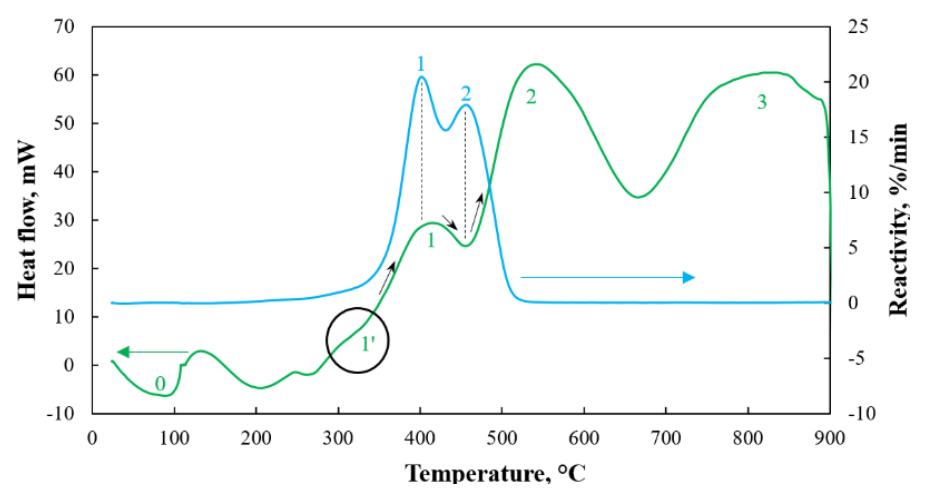

Fig. 5. The heat flow and reactivity as a function of temperature.

Based on the deconvoluted profiles of reactivity, for each constituent a set of kinetic parameters was calculated according to models A and B and summarized in Table 3.

Table 3. Sets of kinetic parameters describing pyrolysis of waste tyres sample (model B and A).

\begin{tabular}{|c|c|c|c|c|c|}
\hline & $\begin{array}{c}\text { Temperature } \\
\text { range }\end{array}$ & $\begin{array}{c}\text { Activation energy, } \\
\text { E }\end{array}$ & $\begin{array}{l}\text { Pre-exponential } \\
\text { factor, } k_{0}\end{array}$ & $\begin{array}{l}\text { Fraction of the } i^{\text {th }} \\
\text { component, } Y\end{array}$ & \\
\hline & ${ }^{\circ} \mathrm{C}$ & $\mathrm{kJ} / \mathrm{mol}$ & $1 / \mathrm{s}$ & $\%$ & \\
\hline Peak 1' & $260-480$ & 68.6 & $4.04 \times 10^{3}$ & 9.2 & \\
\hline Peak 1 & $360-460$ & 268.9 & $3.00 \times 10^{18}$ & 40.5 & A \\
\hline Peak 2 & $400-570$ & 149.2 & $4.75 \times 10^{8}$ & 50.3 & \\
\hline Total & $370-500$ & 41.1 & 4.62 & 100 & B \\
\hline
\end{tabular}

In the case of model $\mathrm{A}$, the activation energies determined for the three constituents of waste tyre are $68.6,268.9$ and $149.2 \mathrm{~kJ} / \mathrm{mol}$, while the pre-exponential factors vary from $4.04 \times 10^{3}$ to $3.00 \times 10^{18}$. Obtained values are similar to these presented in literature, e.g. in paper of Chen et al. [26] for industrial non-tyre rubber waste. According to [26], the activation energy of reaction, reaching its maximum at $360^{\circ} \mathrm{C}$, is about $69 \mathrm{~kJ} / \mathrm{mol}$ and it is almost the same as that obtained for peak 1' (reaching its maximum at $370{ }^{\circ} \mathrm{C}$ ). In both papers, the peak achieves its maximum rate at $400-420^{\circ} \mathrm{C}$ and it has the highest activation energy of $268.9 \mathrm{~kJ} / \mathrm{mol}$ and about $166 \mathrm{~kJ} / \mathrm{mol}$ respectively. Chen et al. [26] discovers three constituents being evolved with maximum rate in temperatures from 470 to $510^{\circ} \mathrm{C}$, while in this paper only one reaction was observed (the peak 2) in this range. Nevertheless, the activation energies presented in [26] are from about 106 to $128 \mathrm{~kJ} / \mathrm{mol}$, while in the present 
study E of peak 2 is $149.2 \mathrm{~kJ} / \mathrm{mol}$. In case of the pre-exponential factors, the discrepancies between the obtained results and the data presented in [26] are higher. Nevertheless, some correlations are still visible. The kinetic parameters determined with the use of model B are also close to these found in the literature. The obtained activation energy of $41.1 \mathrm{~kJ} / \mathrm{mol}$ is close to values determined by Singh et al. [27] for the automotive tyre waste $(53.2-64.6 \mathrm{~kJ} / \mathrm{mol})$. Some discrepancies between obtained and cited results may be attributed to differences in process conditions (e.g. the heating rate), sample composition and variations of kinetic parameters, known as compensation effect [28]. Thermochemical processes such as pyrolysis is being extensively developed by researchers [9, 29] as it seems to be a promising mechanism to deal with a variety of waste and the energy content of the samples tested in this study support the potential even further.

\section{Conclusion}

The experimental investigation carried out in this paper has proven the potential of waste tyres to be used as a fuel for thermochemical processes.

The heating value of the sample is as high as $36.83 \mathrm{MJ} / \mathrm{kg}$, the fuel ratio is 0.36 and $\mathrm{C}$ content is around $80-90 \%$. These parameters clearly indicate the feasibility of scrap tyres as a fuel for pyrolysis. Additionally, the low moisture content makes them even more attractive since an additional drying does not have to be implemented. However, a relatively high sulphur content is present. TG/DSC analysis have provided valuable information to design the laboratory or potentially industrial scale process parameters. It was observed that temperature range $350-500^{\circ} \mathrm{C}$ featured the most rapid volatilisation. Thus, to ensure the entire decomposition of organic matter in tyres, a temperature of $600^{\circ} \mathrm{C}$ seems to be the most suitable for the pyrolysis of waste tyres. The presence of several process stages was proven by the TG/DSC analysis and the obtained kinetic parameters can be considered as reference for experiments design.

The performed analysis and the comparison of the obtained results with those reported in literature allow to conclude that whole WT - not only the rubber - can be considered as a suitable source of sustainable energy through thermochemical processes such as pyrolysis.

The paper was financial supported by Department of Air Conditioning, Heating, Gas Engineering and Air Protection; Wroclaw University of Science and Technology (No. 0401/0055/18).

\section{References}

1. ETRMA, European Tyre \& Rubber Industry. Statistics Edition 2017 N.9. (Brussels, Belgium, 2017)

2. A. Wojciechowski, R. Michalski, E. Kamińska, Polimery 57, 656-60 (2012)

3. J. Malinauskaite, H. Jouhara, D. Czajczyńska, P. Stanchev, E. Katsou, P. Rostkowski, Energy 141, 2013-44 (2017)

4. G. G. Choi, S. H. Jung, S. J. Oh, J. S. Kim, Fuel Process Technol. 123, 57-64 (2014)

5. I. Hita, M. Arabiourrutia, M. Olazar, J. Bilbao, J. M. Arandes, P. Castano, Renew. Sustain. Energy Rev. 56, 745-59 (2016)

6. N. Antoniou, G. Stavropoulos, A. Zabaniotou, Renew. Sustain. Energy Rev. 39, 1053-73 (2014)

7. J. Zeaiter, F. Azizi, M. Lameh, D. Milani, H. Y. Ismail, A. Abbas, Renew. Energy 123, 44-51 (2018) 
8. H. Jouhara, D. Ahmad, D. Czajczyńska, H. Ghazal, L. Anguilano, A. Reynolds, Therm. Sci. Eng. Prog. 5, 579-88 (2018)

9. H. Jouhara, D. Czajczyńska, H. Ghazal, R. Krzyżyńska, L. Anguilano, A.J. Reynolds, Energy 139, 485-506 (2017)

10. D. Czajczyńska, L. Anguilano, H. Ghazal, R. Krzyżyńska, A.J. Reynolds, N. Spencer, Therm. Sci. Eng. Prog. 3, 171-97 (2017)

11. X. Zheng, Z. Ying, B. Wang, C. Chen, Appl. Therm. Eng. 144, 242-7 (2018)

12. Y. Shen, X. Chen, X. Ge, M. Chen, J. Environ. Manage. 214, 94-103 (2018)

13. J. M. Heikkinen, J. C. Hordijk, W. De Jong, H. Spliethoff, J. Anal. Appl. Pyrolysis 71, 883-900 (2004)

14. A. M. Azeez, D. Meier, J. Odermatt, T. Willner, Energy \& Fuels 24, 2078-85 (2010)

15. S. V. Vassilev, C. G. Vassileva, V. S. Vassilev, Fuel 158, 330-50 (2015)

16. J. M. Encinar, J. F. González, J. González, Fuel Process Technol. 68, 209-22 (2000)

17. R. Moliner, I. Suelves, J. Anal. Appl. Pyrolysis 47, 111-25 (1998)

18. P. T. Williams, Waste Manag. 33, 1714-28 (2013)

19. D. Czajczyńska, R. Krzyżyńska, H. Jouhara, N. Spencer, Energy 134, 1121-31 (2017)

20. D. Czajczyńska, R. Krzyżyńska, H. Jouhara, Proceedings 2, 1455 (2018)

21. J. Kandasamy, I. Gökalp, Energy \& Fuels 29, 346-54 (2014)

22. J. F. Gonzalez, J. M. Encinar, J. L. Canito, J. J. Rodriguez, Inter. Symp. Anal. App. Pyrolysis 59, 667-83 (2001)

23. M. I. Rofiqul, H. Haniu, A. B. M. Rafiqul, Fuel 87, 3112-22 (2008)

24. M. R. Islam, H. Haniu, J. Fardoushi, Waste Manag. 29, 668-77 (2009)

25. M. Kyari, A. Cunliffe, P. T. Williams, Energy \& Fuels 19, 1165-73 (2005)

26. R. Chen, Q. Li, Y. Zhang, X. Xu, D. Zhang, Fuel 235, 1224-37 (2019)

27. R. Kumar Singh, B. Ruj, A. Jana, S. Mondal, B. Jana, A. Kumar Sadhukhan, J. Anal. Appl. Pyrolysis 135, 379-89 (2018)

28. K. M. Czajka, J. Anal. Appl. Pyrolysis 133, 82-90 (2018)

29. H. Jouhara, T. K. Nannou, L. Anguilano, H. Ghazal, N. Spencer, Energy 139, 1210-30 (2017) 